\title{
MUCOID VARIATION IN PSEUDOMONAS AERUGINOSA INDUCED BY THE ACTION OF PHAGE
}

\author{
DiANA R. MARTIN* \\ Cross-Infection Reference Laboratory, Central Public Health Laboratory, \\ Colindale Avenue, London, NW9 $5 H T$
}

Spontaneous variation from the mucoid to the non-mucoid colonial form is often seen in strains of Pseudomonas aeruginosa isolated from patients, but the reverse change has rarely been reported. Williamson (1956) described the change from the non-mucoid to the mucoid form after passage through Eugon broth enriched with potassium gluconate, but Wahba (1964) was unable to repeat this. Zierdt and Schmidt (1964) suggested that an example of this change that they observed had been caused by the action of phage, but no evidence for this was given.

The particular association of the mucoid colonial form of $P$. aeruginosa with disease of the respiratory tract, and especially with cystic fibrosis, has frequently been described (Iacocca, Sibinga and Barbero, 1963; Burns and May, 1968; Doggett, 1969; Diaz and Neter, 1970), and evidence is accumulating that the change from the non-mucoid to the mucoid form may occur in the human body (Doggett et al., 1966; Diaz and Neter). Doggett et al. (1966) observed that non-mucoid always preceded mucoid forms in the patient, and suggested that naturally occurring mucoid variants were selected.

In the course of routine phage typing of $P$. aeruginosa, I observed that on some plates the lawn of bacterial growth immediately around areas of phage lysis was altered. Two main types of change were seen: (1) sometimes the area of lysis was surrounded by a halo of less dense bacterial growth and (2) at other times it was surrounded by a ring of wet slimy growth, which sometimes also covered the area of lysis. The former change was taken to be due to the phage-associated depolymerase described by Bartell, Orr and Lam (1966); subcultures from this type of halo invariably produced normal colonies. Subcultures from the areas of slimy growth, on the other hand, resulted in the appearance of mucoid growth. The properties of this artificial type of mucoid variant were compared with those of naturally occurring mucoid strains.

\section{MATERIALS AND METHODS}

Cultures. All the cultures of $P$. aeruginosa had been received for phage typing from hospital and public health laboratories or isolated in the course of my own epidemiological investigations. The following strains isolated from patients were examined in detail: nos. 9, 1946, 2034, 3261, 3830, 3841 and 9778.

Phage typing. The typing set comprised 20 phages, stocks of which had been prepared in the Cross-Infection Reference Laboratory (see Lowbury et al., 1970).

Received 1 July 1972; accepted 8 Aug. 1972.

* Present address: School of Mathematics and Science, Wellington Polytechnic, Wellington, New Zealand. Requests for reprints should be sent to the London address.

J. MED. MICROBIOL.-VOL. 6 (1973) 
Serological typing. Strains were typed by agglutination according to the system of Habs (1957; see also Lowbury et al.).

Colonial forms. These were recognised from the descriptions of Wahba and Darrell (1965) on plates of medium A (King, Ward and Raney, 1954).

High-speed centrifugation of phage preparations. Concentrated phage preparations were centrifuged for $1 \mathrm{hr}$ at $60,000 \mathrm{~g}$ to deposit phage. The supernate was titrated and spotted on to a lawn of indicator organisms.

Neutralisation with phage antiserum. Equal volumes $(0.5 \mathrm{ml})$ of phage preparation at routine test dilution (RTD) and phage antiserum diluted 1 in 50 were mixed and incubated at $37^{\circ} \mathrm{C}$ for $1 \mathrm{hr}$. The mixture was then titrated and spotted on to a lawn of indicator organisms.

Heat-inactivation of phage preparations. One $\mathrm{ml}$ of phage preparation at RTD was heated for $1 \mathrm{hr}$ to a temperature known to be lethal to the phage (Elizabeth $\mathrm{H}$. Asheshov, unpublished). The phage preparation was then titrated and spotted on to a lawn of indicator organisms.

Precipitation of extracellular materials. Growth from cultures on nutrient agar was suspended in physiological saline and centrifuged. The supernatant fluid was precipitated with a mixture of ethanol and benzene $(1: 1 \mathrm{v} / \mathrm{v})$ in proportions of 1 volume of supernate to 9 volumes of precipitant mixture (Doggett, Harrison and Wallis, 1964). An alternative method of precipitation with a mixture of acetone and alcohol $(3: 1 \mathrm{v} / \mathrm{v})$ in the proportion of 1 volume of supernatant to 3 volumes of mixture (Kwapinski, 1965) was also used.

Staining of extracellular material. Films were stained with alcian blue by the method of McKinney (1953). Polysaccharide material stained blue and cells were counterstained with carbol fuchsin.

Uronic acid assay. The method of Dische (1947) was used. Readings were made at $535 \mathrm{~nm}$ and compared with a standard glucuronic-acid curve.

\section{Results \\ Production of mucoid variants}

With all except two of the phages of the typing set, "sliming" appeared around or over the areas of lysis of appropriate strains of $P$. aeruginosa. The two exceptions, nos. 31 and col. 18, were phages that gave cloudy plaques. With over one-half of all strains typed, areas of " sliming " appeared around at least one area of phage lysis, and these were consistently present when typing was repeated. When phage was applied at different dilutions, sliming was observed equally well around areas of confluent lysis and around single plaques.

Subculture from the slimy area on to blood agar usually resulted in extensive areas of lysis of the culture due to the carry-over of free phage, but mucoid growth was again observed at the edge of the lytic area. Continued subculture from a mucoid area usually resulted in pure cultures of mucoid colonies that could be indefinitely propagated, although in a few instances it was not possible to establish mucoid progeny.

Like the naturally occurring mucoid strains, the phage-induced mucoid variants gave rise to non-mucoid forms either as outgrowths from the edge of a mucoid colony or as single colonies. The phage-typing patterns of the phage-induced mucoid variants were similar to those of the parent strains and in all cases the variant continued to be susceptible to lysis by the phage that had been responsible for its induction. Mucoid variants belonged to the same serotype as did the parent strain. 


\section{Conditions for the induction of mucoid variation}

The simplest explanation for the appearance of mucoid growth in the area of phage lysis - that the phage acted selectively by lysing the non-mucoid population while allowing mucoid variants to survive-seemed unlikely because the mucoid organisms were invariably sensitive to the phage that had given rise to their appearance. Moreover, fluctuation tests (Luria and Delbrück, 1943) showed a non-random distribution in the number of mucoid colonies when replicate colonies were spread on phage-containing agar. Mucoid variants were therefore not spontaneous mutants that had arisen during the growth of the parent strain.

Reduction in the titre of the phage preparations occurred after high-speed centrifugation, heat inactivation and neutralisation with phage antiserum. When preparations so treated were applied to cultures, sliming was not observed at dilutions higher than those at which lysis could be detected. It appeared, therefore, that the presence of phage was necessary for the induction of mucoid variation.

\section{Recovery of phage from phage-induced mucoid variants}

Cross-streaking of a fresh culture of the mucoid variant on to the nonmucoid parent strain resulted in lysis of the latter. Examination of the supernatants obtained from two strains, $9 \mathrm{~m}$ (isolated from an area of lysis of strain 9 by phage no. 7) and $2691 \mathrm{~m}$ (isolated from an area of lysis of strain 2691 by phage no. 109), showed that the phage present in each supernatant had a similar lytic spectrum to that of the inducing phage and was inactivated by antiserum to that phage. Phage present in the supernate of cultures of the parent strains had a different lytic spectrum.

Phage obtained from the supernatant of the induced mucoid variant caused sliming when applied to lawns of the non-mucoid parent strain. Nonmucoid forms isolated from induced mucoid variants also produced mucoid progeny when subjected to the inducing phage.

\section{Comparison of phage-induced and naturally occurring mucoid strains}

Precipitation of extracellular material. The supernate of three phageinduced mucoid strains (nos. $9 \mathrm{~m}, 2034 \mathrm{~m}$, and $2691 \mathrm{~m}$ ) and five naturally occurring mucoid strains (nos. 1946, 3261, 3830, 3841, and 9778) all produced a white stringy water-soluble precipitate on addition of the ethanol-benzene mixture. Non-mucoid variants of each of the naturally occurring mucoid strains when similarly treated gave no such precipitate.

The supernates of three mucoid strains (nos. 9m, 3261, 3841) were treated with the acetone-alcohol mixture $(3: 1 \mathrm{v} / \mathrm{v})$. When this was added slowly to the supernate, two distinct precipitates with differing characteristics appeared successively. The first precipitate formed (precipitate A) was stringy and could be removed by rotating a glass rod in the mixture. This stringy material 
ceased to be formed after 2-3 volumes of the precipitant mixture had been added, the exact amount varying from strain to strain. Further addition of the precipitant mixture resulted in a flocculent precipitate (precipitate B) which could be removed by centrifugation. Addition of acetone-alcohol to the supernate of the non-mucoid forms of these strains produced only a flocculent precipitate (table I).

Uronic acid assay. The precipitates obtained in the preceding experiment were examined for uronic acid content (table I). The precipitate A from each

\section{TABLE I}

Properties of naturally occurring and phage-induced mucoid forms of Pseudomonas aeruginosa and the corresponding non-mucoid forms

\begin{tabular}{|c|c|c|c|c|}
\hline $\begin{array}{l}\text { Number } \\
\text { of strain }\end{array}$ & Origin of strain & $\begin{array}{c}\text { Precipitates obtained* } \\
\text { on addition of } \\
\text { acetone }: \text { alcohol } \\
(3: 1 \mathrm{v} / \mathrm{v})\end{array}$ & $\begin{array}{l}\text { Percentage of } \\
\text { uronic acid in } \\
\text { precipitates }\end{array}$ & $\begin{array}{c}\text { O specificity of } \\
\text { substances } \\
\mathrm{A} \text { and } \mathrm{B} \dagger\end{array}$ \\
\hline 9 & Wild strain (non-mucoid) & flocculent (B) & $2 \cdot 5$ & + \\
\hline $9 \mathrm{~m}$ & $\begin{array}{l}\text { Induced in strain } 9 \text { with } \\
\text { phage } 7\end{array}$ & $\left\{\begin{array}{l}\text { stringy (A) } \\
\text { flocculent (B) }\end{array}\right.$ & $\begin{array}{r}27 \cdot 0 \\
1 \cdot 0\end{array}$ & $\bar{t}$ \\
\hline 3261 & Spontaneous variant & flocculent (B) & 1.0 & + \\
\hline $3261 \mathrm{~m}$ & $\begin{array}{l}\text { of } 326 \mathrm{~lm} \\
\text { Wild strain (mucoid) }\end{array}$ & $\left\{\begin{array}{l}\text { stringy (A) } \\
\text { flocculent (B) }\end{array}\right.$ & $\begin{array}{r}25 \cdot 0 \\
1 \cdot 0\end{array}$ & $\overline{+}$ \\
\hline 3841 & $\begin{array}{l}\text { Spontaneous variant } \\
\text { of } 3841 \mathrm{~m}\end{array}$ & flocculent (B) & $2 \cdot 5$ & + \\
\hline $3841 \mathrm{~m}$ & $\begin{array}{l}\text { of } 3841 \mathrm{~m} \\
\text { Wild strain (mucoid) }\end{array}$ & $\left\{\begin{array}{l}\text { stringy } \\
\text { flocculent } \\
(\mathrm{B})\end{array}\right.$ & $\begin{array}{r}17 \cdot 5 \\
2 \cdot 5\end{array}$ & $\overline{+}$ \\
\hline
\end{tabular}

* See text.

$++=$ Gave precipitate with $\mathrm{O}$ antiserum for the type; $-=$ no such precipitate.

mucoid strain contained considerable amounts of uronic acid (17.5-27 per cent.), whereas the precipitate B obtained from both mucoid and non-mucoid forms contained little uronic acid $(<2.5$ per cent.).

Serological activity of precipitates. Solutions in physiological saline containing $1 \mathrm{mg}$ per $\mathrm{ml}$ of each precipitate obtained from each strain were tested with each of the $P$. aeruginosa antisera by the capillary precipitation test (Swift, Wilson and Lancefield, 1943). None of the precipitates A showed any serological activity, but in all cases precipitate B showed the same Ospecificity as had been demonstrated by agglutination tests with the corresponding whole cells.

Staining of bacterial cells. No difference could be seen between phageinduced and naturally occurring mucoid cultures when stained with alcian blue. Cells of mucoid strains appeared embedded in strings of polysaccharide material. 
Frequency of the mucoid form among Pseudomonas aeruginosa strains isolated from various sites

Of 1442 isolates from a variety of sources in many different hospitals (table II) only 105 ( 7 per cent.) were mucoid in colonial form; but there were 95 mucoid cultures among 433 ( 22 per cent.) that had been isolated from the respiratory tract.

TABLE II

Colonial types of $P$. aeruginosa cultures isolated from various sites

\begin{tabular}{|c|c|c|c|c|c|}
\hline \multirow[b]{2}{*}{ Site of isolation } & \multirow{2}{*}{$\begin{array}{l}\text { Total number } \\
\text { examined }\end{array}$} & \multicolumn{4}{|c|}{ Number of cultures of colonial type* } \\
\hline & & 1 & 2 & 3 & 4 \\
\hline Respiratory tract & 433 & 298 & 36 & 4 & 95 \\
\hline Urine & 87 & 76 & 7 & 0 & 4 \\
\hline Wound & 261 & 241 & 17 & 1 & 2 \\
\hline Other body site & 210 & 187 & 12 & 8 & 3 \\
\hline Hospital environment & 361 & 309 & 40 & 11 & 1 \\
\hline Not known & 90 & 85 & 3 & 2 & 0 \\
\hline
\end{tabular}

* Recorded after 24 hours' incubation on King's medium A (King et al.). Colonial types as described by Wahba and Darrell; type 1, large, fiat, granular; type 2, small, round; type 3, rough, dry; type 4, mucoid.

TABLE III

The frequency of the mucoid form among $P$. aeruginosa strains isolated from different classes of respiratory disease

\begin{tabular}{|c|c|c|c|}
\hline \multirow[b]{2}{*}{$\begin{array}{l}\text { Hospital } \\
\text { number }\end{array}$} & \multicolumn{3}{|c|}{ Proportion mucoid/total among isolates* from } \\
\hline & cystic fibrosis & $\begin{array}{l}\text { other chronic } \\
\text { respiratory } \\
\text { disease }\end{array}$ & $\begin{array}{l}\text { acute infection or } \\
\text { colonisation of the } \\
\text { respiratory tract }\end{array}$ \\
\hline $\begin{array}{l}1 \\
2 \\
3\end{array}$ & $\begin{array}{c}0 / 0 \\
42 / 74 \\
21 / 37\end{array}$ & $\begin{array}{l}0 / 0 \\
0 / 0 \\
5 / 21\end{array}$ & $\begin{array}{l}1 / 63 \\
0 / 11 \\
0 / 0\end{array}$ \\
\hline All & $63 / 111$ & $5 / 21$ & $1 / 74$ \\
\hline
\end{tabular}

Among the strains from respiratory sources were collections from three hospitals in which records had been kept of the colonial form at the time of isolation and of the clinical history of the patient (table III). In hospital 1, all the isolates were from patients with acute respiratory-tract infection or colonisation, mainly in an intensive-care unit and often after mechanically assisted ventilation; only one of 64 was mucoid. Most of the strains from hospital 2-a children's hospital-were from cases of cystic fibrosis and 42 of 74 of these were mucoid; all 11 of the isolates from acute respiratory infection 
were non-mucoid. The collection from hospital 3 included strains isolated from other chronic respiratory-tract infections, such as chronic bronchitis and bronchiectasis, and these also included a considerable proportion in the mucoid form.

\section{DISCUSSION}

Change from the non-mucoid to the mucoid form in laboratory experiments is of considerable interest because a similar change in the host tissues has already been postulated. With the methods used, it was not possible to select mucoid variants from non-mucoid cultures. Mucoid colonies were observed only in the presence of phage and appeared to depend for their initiation on a phage lytic cycle. The phage-induced mucoid variants remained sensitive to lysis by the inducing phage and this excluded the possibility that the colonial change resulted from lysogenic conversion. Transduction appears an unlikely explanation because none of the propagating strains for the phages that induced mucoid variation were themselves mucoid. Neither the naturally occurring nor the phage-induced mucoid forms are stable; both eventually revert to the non-mucoid form during laboratory subculture.

Sapelli and Goebel (1964) described a similar change from the non-mucoid to the mucoid form when Escherichia coli K12 was plated with an excess of phage T6. The term "pseudolysogeny" has been used by Hayes (1968) to describe the state in which the co-existence of virulent phage with genotypically sensitive bacteria is associated with a temporary inability of the bacteria to absorb the phage. Under these circumstances phage is present in the population as free particles and is not carried inside individual bacteria. Examples that have been described include the phage-mediated change in colony form of Brucella abortus (Jones, McDuff and Wilson, 1962), and the phenotypic change in utilisation of lactose and mannose observed in Shigella dysenteriae (Li, Barksdale and Garmise, 1961). The results obtained in this study parallel closely the findings reported by these workers, and it is possible that the mucoid forms of $P$. aeruginosa may represent the state of " pseudolysogeny".

Mucoid strains have been shown to possess a distinct polysaccharide material (Carlson and Matthews, 1966) which differs from the normal extracellular material containing the determinants of $\mathrm{O}$-antigenicity and possessed by all strains (Bartell, Orr and Chudio, 1970). Conflicting reports about the composition of pseudomonas "slime" probably reflect differences in the colonial form of the strains studied, and, and a lack of precision in the use of the word "slime". Workers who have examined the "slime" of specified mucoid variants all describe the presence of guluronic and mannuronic acids in it (Linker and Jones, 1964; Carlson and Matthews; Bjornson and Michael, 1970). I obtained two distinct precipitates from the extracellular material of mucoid strains but only one precipitate from non-mucoid forms. The precipitate peculiar to the mucoid strains contained uronic acids in quantities comparable to those reported by Linker and Jones, and by Carlson and Matthews, and the precipitate common to the mucoid and the non-mucoid strains contained $\mathrm{O}$ antigen. The characters of the phage-induced variants 
were indistinguishable from those of naturally occurring mucoid strains isolated from clinical sources.

Mucoid $P$. aeruginosa appears to be particularly common in the sputum in cystic fibrosis, but also occurs with considerable frequency in other chronic infections of the respiratory tract. If the mucoid variants that appear in the human body arise as a result of phage action, the most likely source of inducing phages is other strains of $P$. aeruginosa; and it may be that the diseases in which mucoid variants appear are those in which patients are liable to successive infections with different strains of $P$. aeruginosa. Maintenance of the mucoid form appears to depend on the presence of phage in the lytic cycle, and in the laboratory it can in most cases be maintained for long periods of time only by regular selection of colonies. A corresponding selective advantage for the mucoid variant in the respiratory tract might achieve the same end.

\section{SUMMARY}

Mucoid colonial forms of Pseudomonas aeruginosa were obtained by subculture from areas of "sliming" around zones of lysis on phage-typing plates. These mucoid forms were not spontaneous variants, but depended on the presence of phage in the lytic cycle for their initiation and continued existence. The properties of naturally occurring and phage-induced mucoid forms were similar. The mucoid colonial form was observed frequently only in patients with chronic disease of the respiratory tract.

I am grateful to all those who gave me information about cultures submitted for typing, and particularly to Dr I. Phillips, Dr C. T. Keane, and Professor J. R. May. I wish to thank Mr T. L. Pitt for his excellent technical assistance.

\section{REFERENCES}

Bartell, P. F., ORR, T. E., AND ChUdio, B. 1970. Purification and chemical composition of the protective slime antigen of Pseudomonas aeruginosa. Infect. Immun., 2, 543.

Bartell, P. F., OrR, T. E., and Lam, Grace K. H. 1966. Polysaccharide depolymerase associated with bacteriophage infection. J. Bact., 92, 56.

BJoRnson, ANN B., AND Michael, J. G. 1970. Biological activities of rabbit immunoglobulin $\mathrm{M}$ and immunoglobulin $\mathrm{G}$ antibodies to Pseudomonas aeruginosa. Infect. Immun., 2, 453.

BURNS, M. W., AND MAY, J. R. 1968. Bacterial precipitins in serum of patients with cystic fibrosis. Lancet, 1, 270.

Carlson, D. M., AND Matthews, L. W. 1966. Polyuronic acids produced by Pseudomonas aeruginosa. Biochemistry, N.Y., 5, 2817.

Diaz, F., AND NeTER, E. 1970. Pseudomonas aeruginosa: serogroups and antibody response in patients with neoplastic diseases. Amer. J. med. Sci., 259, 340.

DisCHE, Z. 1947. A new specific color reaction of hexuronic acids. J. Biol. Chem., 167, 189.

DoGgetT, R. G. 1969. Incidence of mucoid Pseudomonas aeruginosa from clinical sources. Appl. Microbiol., 18, 936.

Doggett, R. G., Harrison, G. M., Stillwell, R. N., AND Wallis, E. S. 1966. An atypical Pseudomonas aeruginosa associated with cystic fibrosis of the pancreas. J. Pediat., 68, 215.

Doggett, R. G., HaRrison, G. M., AND Wallis, E. S. 1964. Comparison of some properties of Pseudomonas aeruginosa isolated from infections in persons with and without cystic fibrosis. J. Bact., 87, 427. 
HABS, I. 1957. Untersuchungen über die O-Antigene von Pseudomonas aeruginosa. Z. Hyg. InfektKrankh., 144, 218.

HAYES, W. 1968. The genetics of bacteria and their viruses. Oxford, 2nd Edit., p. 448.

IACOCCA, V. F., Sibinga, M. S., AND BARbero, G. J. 1963. Respiratory tract bacteriology in cystic fibrosis. Amer. J. Dis. Child., 106, 315.

Jones, LoIs M., MCDuff, C. R., AND WILson, J. B. 1962. Phenotypic alterations in the colonial morphology of Brucella abortus due to a bacteriophage carrier state. J. Bact., 83, 860 .

King, Elizabeth O., Ward, Martha K., and Raney, D. E. 1954. Two simple media for demonstration of pyocyanin and fluorescin. J. Lab. Clin. Med., 44, 301.

KWAPINSKI, J. B. 1965. Methods of serological research. New York, p. 25.

LI, K., Barksdale, L., AND Garmise, L. 1961. Phenotypic alterations associated with the bacteriophage carrier state of Shigella dysenteriae. J. Gen. Microbiol., 24, 355.

LINKER, A., AND JoNEs, R. S. 1964. A polysaccharide resembling alginic acid from a Pseudomonas micro-organism. Nature, Lond., 204, 187.

Lowbury, E. J. L., Thom, B. T., Lilly, H. A., BabB, J. R., AND Whittall, K. 1970. Sources of infection with Pseudomonas aeruginosa in patients with tracheostomy. J. Med. Microbiol., 3, 39.

LuRIA, S. E. AND DelbrüCK, M. 1943. Mutations of bacteria from virus sensitivity to virus resistance. Genetics, Princeton, 28, 491.

MCKINNEY, R. E. 1953. Staining bacterial polysaccharides. J. Bact., 66, 453.

SaPelli, Rose V., AND Goebel, W. F. 1964. The capsular polysaccharide of a mucoid variant of E. coli K12. Proc. Natn. Acad. Sci., USA, 52, 265.

SwifT, H. F., Wilson, A. T., AND LANCEFIELD, ReBeCCA C. 1943. Typing group A hemolytic streptococci by $\mathrm{M}$ precipitin reactions in capillary pipettes. J. Exp. Med., 78, 127.

WaHba, A. H. 1964. Epidemiology of hospital infection with Pseudomonas pyocyanea. Ph.D. Thesis, University of London.

Wahba, A. H., AND Darrell, J. H. 1965. The identification of atypical strains of Pseudomonas aeruginosa. J. Gen. Microbiol., 38, 329.

Williamson, C. K. 1956. Morphological and physiological considerations of colonial variants of Pseudomonas aeruginosa. J. Bact., 71, 617.

ZIERDT, C. H., AND SCHMIDT, P. J. 1964. Dissociation in Pseudemonas aeruginosa. J. Bact.. 87, 1003. 